\title{
XLIV. Some new methods for separating uranium $X$ from uranium
}

\author{
Richard B. Moore B.Sc. \& Herman Schlundt Ph.D.
}

To cite this article: Richard B. Moore B.Sc. \& Herman Schlundt Ph.D. (1906) XLIV. Some new methods for separating uranium X from uranium , Philosophical Magazine Series 6, 12:70, 393-396, DOI: $10.1080 / 14786440609463552$

To link to this article: http://dx.doi.org/10.1080/14786440609463552

Published online: 16 Apr 2009.

Submit your article to this journal $₫$

Џ Article views: 2

Q View related articles $\square$

Citing articles: 5 View citing articles 5 
XLIV. Some Neu Methods for Separating Uranium $X$ from Uranium. By Richard B. Moore, B.Sc., Professor of Chemistry, Butler College, Indianapolis, U.S.A., and Herman Schlundt, Ph.D., Assistart Professor of Physical Chemistry, University of Missouri, U.S.A.*

T 1900 , by adding ammonium carbonate to solutions of uranium salts until the precipitate which first formed redissolved, Sir William Crookest was able to separate that portion of the uranium salt which was active to a photographic plate. He showed that the minute undissolved residue, which was mostly due to impurities in the salt, was one hundred times more active, weight for weight, than the uranium from which it had been separated. He also showed that a partial separation could be made by dissolving crystallized uranium nitrate in ether. Under such conditions the uranium divides itself between the ether and water in unequal proportions. That portion in the water layer was intensely active to the photographic plate, whilst that in the ether, although its activity had been only slightly reduced when measured by the electrical method, was practically inactive photographically. The explanation for these results was given by Soddy $\ddagger$, and by Rutherford and Grier $\$$, who showed that a radio-active constituent, to which Crookes gave the name uranium $X$, had been separated by the above processes from the parent uranium, and that this $\mathrm{Ur} \mathrm{X}$ gave rise to all of the $\beta$ rays but to none of the $\alpha$ rays.

Becquerel \| obtained similar results by another method. He found that when barium sulphate was precipitated in a uranium nitrate solution a portion of the $\mathrm{Ur}_{\mathrm{r}} \mathrm{X}$ was carried down with the precipitate. By a number of precipitations the uranium ultimately became almost inactive photographically.

Recently we have confirmed the above methods of separation of Ur $\mathrm{X}$ from radium, and in addition have obtained several new methods for making the separation, which give still better results. The details of the experiments follow.

Five grams of crystallized uranium nitrate (Kahlbaum's best 1 ) was dissolved in about 60 c.c. of acetone. The solution was slightly cloudy, probably in consequence of the presence of

* Communicated by the Authors.

† Proc. Roy. Soc. lxvi. p. 409 (1900).

I Trans. Chem. Soc. Ixxxi. p. 460 (1902).

\$ Phil. Mag, Sept. 1902.

II C. $R$. cxxxi. p. 137 (1900); cxxxiii. p. 977 (1901).

9. McCoy has shown that this does not contain radium. Phil. Mag. Jan. 1906. 
a small amount of basic nitrate. This residue was filtered off; washed three times with acetone, and tested by the photographic method. It was found to be exceedingly active, an excellent radiograph being obtained in sixty hours. On testing the uranium nitrate in the filtrate it proved to be only slightly active to a photographic plate. Several samples of uranium nitrate of different degrees of purity were tested in the same way. Generally speaking, the larger the amount. of insoluble residue the better the separation. If, after the insoluble residue is filtered off, a small amount of moist freshly precipitated ferric hydroxide be stirred into the clear filtrate, the uranium nitrate is practically freed from $\mathrm{UrX}$. The ratio of the amounts of $\operatorname{UrX}$ contained in the insoluble residue and in the ferric bydroxide varies to a certain extent with the sample of uranium nitrate used. In one experiment the ratio between the activities, as measured by a Dolezalek quadrant-electrometer and the usual testing vessel, in the insoluble residue and in the ferric hydroxide, was as 9 to 11 . In a similar experiment the insoluble residue was more active, the ratio being almost 2 to 1 .

Another 5 gram sample of the nitrate was dissolved in acetone, and, without filtering, moist ferric hydroxide was stirred into the liquid. On filtering the solution and washing the residue with acetone, the latter was found to contain all of the $\beta$ activity of the original sample, the uranium obtained from the filtrate giving no effect on a photographic plate after an exposure of five days.

$\mathrm{Ur} \mathrm{X}$ can be separated from uranium in the same manner by using the following solvents instead of acetone :-Methyl acetate, ethyl acetate, methyl, ethyl, and amyl alcohols, and aceto-acetic-ether. In all cases the separated UrX was not only recognized by the photographic method, but the curves of decay were also taken by the electrical method, the $\beta$ activity decaying to half value in about 22 days. The same variation in the amount of activity removed, with the sample of nitrate used, noticed in the case of acetone, was also found to hold good with these solvents. In no case was all of the UrX removed by filtering off the small residue which remained insoluble in each liquid. The addition of moist ferric hydroxide, or in the case of a liquid immiscible with water, dry barium sulphate, completes the separation. The barium sulphate, however, does not answer as well as the ferric bydroxide.

The $\mathrm{U}_{1} \mathrm{X}$, no matter which solvent was used to make the separation, always gave off $\alpha$ as well as $\beta$ rays. Rutherford* and Grier found that in the separation by means of ammonium 
Methods for Separating Uranium X from Uranium. 395

carbonate the $\alpha$ rays constituted about one-third of the total activity at the start. It apparently has been assumed that this small amount of $\alpha$ activity belongs to traces of uranium, for $\mathrm{UrX}$ is generally accredited with giving only $\beta$ rays. We found that in the UrX separated by the above methods, not only did the $\beta$ radiation decay according to an exponential law, falling to half value in about 22 days, but the a radiation also decayed and at the same rate. With acetone the proportion of $\alpha$ activity was usually about 50 per cent. of the total activity, although the amount depended to a certain extent upon the sample of nitrate used, and the manner in which the residue to be tested was spread upon the plate. With the other solvents the ratio varied with the solvent and also with the sample of nitrate used.

Fig. 1.

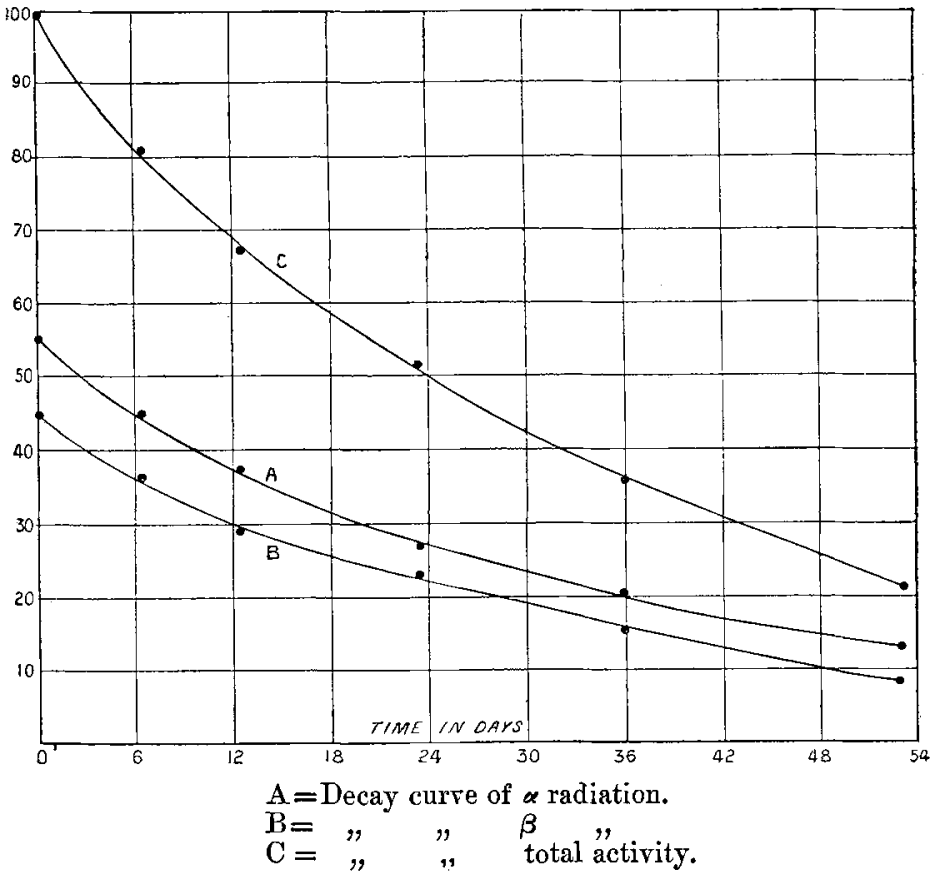

The best curves showing the relation between the rates of decay of the $\alpha$ and $\beta$ radiations were obtained by first filtering off from the insoluble residue and then stirring in a little ferrie bydroxide. By washing with the solvent the hydroxide could be practically freed from uranium, the presence of which would affect the decay rate of the $\alpha$ radiation. Fig. 1 represents the curves of decay obtained in this manner 


\section{Methods for Separating Uranium $X$ from Uranium.}

by means of acetone. The $\beta$ activity was measured by covering the sample with two thicknesses of paper which had previously been tested and shown to cut off all $\alpha$ radiation. The activity due to the a rays was obtained by subtracting the $\beta$ activity from the total activity.

The separation by means of ammonium carbonate does not work well unless there is a considerable amount of undissolved impurity. The presence of ferric hydroxide, either added to or precipitated in the solution, materially aids the separation. The results obtained by us with ammonium carbonate, however, were not nearly so satisfactory as those with acetone and the other solvents mentioned.

In order to see whether the decay curves of $\mathrm{Ur} \mathrm{X}$, obtained by means of ammonium carbonate, were similar to those of Ur X obtained by means of acetone \&c., the following experiment was performed :-12 grms. of Kahlbaum's uranium nitrate was dissolved in 60 c.c. of water. A few drops of dilute ferric chloride solution were then added, followed by ammonium carbonate solution in excess. After filtering, the precipitate was washed with ammonium carbonate solution. It was then redissolved in dilute nitric acid, and reprecipitated with excess of ammonium carbonate in order to get rid of traces of uranium. A few drops of ferric chloride were again added to the first uranium filtrate, and the precipitate thus obtained filtered off and washed with ammonium carbonate. The filter-papers with their precipitates were then incinerated together, and the ferric oxide and ash ground up in alcohol and spread in a very thin layer on a metal tray. The alcohol was burnt off, and after cooling the total activity, as well as that due to the $\alpha$ and $\beta$ radiations, was measured at intervals of several days in the manner described above. The ihree curves representing these activities fell to half value in from 21 to 22 days, and were in every way comparable to those obtained by means of acetone.

We have thus shown, first, that Ur X may be separated from uranium by means of a number of solvents in which $\mathrm{UrX}$ is insoluble, these new methods being more satisfactory than those already in use, and secondly that $\mathrm{Ur} X$ emits not only $\beta$ but also $\alpha$ rays.

Butler College, Indianapolis, Inà.

University of Missouri, Columbia, Mo. 